\title{
RESEARCH
}

Open Access

\section{First-line antiretroviral treatment and virological response among HIV adult patients at an accredited HIV care center, Cameroon}

Juste Patient Mbébi Enoné ${ }^{1}$, Calixte Ida Penda ${ }^{2,3}$, Serge Bruno Ebong ${ }^{1}$, Madeleine Mbangue ${ }^{4}$,

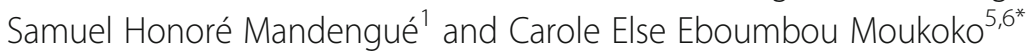

\begin{abstract}
Background: Viral load (VL) monitoring in the clinical follow-up of HIV patients to detect treatment failure is not routinely offered in Cameroon. The study was designed to characterize virological response on antiretroviral treatment (ART) among adults living with HIV and to identify predictors of virological failure (VF).

Methods: Between November 2014 and January 2016, a prospective, population-based cohort study was conducted among HIV-positive adults under first-line treatment and monitored the Accredited HIV Care Center (AHCC) of Laquintinie Hospital of Douala. Clinical and biological data at the initiation of ART were collected from patients' medical records. HIV VL at 12 and 24 months after the patient started treatment on ART were performed using quantitative real-time PCR protocol with the generic HIV Roche TaqMan assay. Descriptive and logistic regression analysis were performed in Stata SE11 version in data analysis.

Results: Overall 150 (45.5\%) of 330 adults living with HIV were tested with at least one VL, and of these patients, 51 (34.0\%) were tested with two VL during the followed-up. The VF was observed in 13 of 51 (25.5\%) patients and among them, $8(61.5 \%)$ switched to second-line ART regimens. Thirty-five $(68.6 \%)$ of the 51 patients had an undetectable $V L$ at the first VL measurement, and seven (13.7\%) patients subsequently developed viral load rebound (VLR) on tritherapy. Using a multivariate analysis, the risk of VF was seven times higher in HIV adults who did not respect the medication hours $(\mathrm{OR}=7.38,95 \% \mathrm{Cl}=1.56-34.90, p=0.012)$ and eleven times higher in patients with none or primary school education $(\mathrm{OR}=11.38,95 \% \mathrm{Cl}=2.41-53.76, p=0.002)$.

Conclusion: Low education level and poor adherence are the main risk factors for VF. Strengthening therapeutic failure prevention strategies and routine VL surveillance would allow early detection of VF and contribute in achieving the third goal of UNAIDS which recommends "90-90-90" targets for People Living with HIV in resourcelimited settings.
\end{abstract}

Keywords: Adult HIV patients, Anti-retroviral therapy, Virological success, Virological failure, Viral load rebound, Cameroon

\footnotetext{
* Correspondence: elsecarole@yahoo.fr; eboumbou@pasteur-yaounde.org

${ }^{5}$ Biological Sciences Department, Faculty of Medicine and Pharmaceutical

Sciences, University of Douala, BP 2701 Douala, Cameroon

${ }^{6}$ Centre Pasteur Cameroon, Douala, Cameroon

Full list of author information is available at the end of the article
}

(c) The Author(s). 2019 Open Access This article is distributed under the terms of the Creative Commons Attribution 4.0 International License (http://creativecommons.org/licenses/by/4.0/), which permits unrestricted use, distribution, and reproduction in any medium, provided you give appropriate credit to the original author(s) and the source, provide a link to the Creative Commons license, and indicate if changes were made. The Creative Commons Public Domain Dedication waiver (http://creativecommons.org/publicdomain/zero/1.0/) applies to the data made available in this article, unless otherwise stated. 


\section{Background}

Despite 33 years of research and efforts, Human Immunodeficiency Virus (HIV) infection remains a major global public health problem particularly in sub-Saharan Africa with 25.8 million of people living with HIV (PLHIV) [1-4]. The Cameroon Demographic and Health Survey estimated the prevalence of $4.3 \%$ among the 1549 years old [5]. This prevalence is not the same in all regions, ranging from $1.2 \%$ in the Far-North to $7.2 \%$ in the South. In addition, the incidence of HIV infection in the general population was estimated at 50,000 in 2011 and 58,630 in $2014[5,6]$.

In spite of the Government's desire to decentralize medical care for PLHIV and the year-to-year increase in the number of HIV Care Centers, the targets of the 2011-2015 National Strategic Plan for the fight against HIV/AIDS and sexually transmissible infections were not reached. By 2014, 65\% of health facilities provided medical care for PLHIV. However, there were stark disparities across regions, with a much lower percentage in some regions [6, 7]. Regarding the effective care, antiretroviral treatment (ART) was introduced in 2003 and has been available free-of-charge since 2007 at all levels of the health system in Cameroon. Between 2013 and 2014, the active list from all regions of PLHIV receiving ART increased by $10.3 \%$, bringing this number to 145 , $038(27.4 \%)$ adult patients and 6099 (11\%) children less than 15 years old on ART in December 2014 [6]. The number of PLHIV in need of ART still remains very high, only $145,038(27.4 \%)$ of the 528,512 PLHIV received ART in 2014.

In addition to scaling up the medical treatment with ART, the National AIDS Control Program must ensure the uninterrupted supply of ART medications, supervision or support of PLHIV under treatment, and biological monitoring to promote treatment success, which has been defined as undetectable viral loads (VL). The World Health Organization (WHO) has recommended since 2010 that emphasis be placed on biological monitoring every six months with CD4-T lymphocytes count measurement for ART initiation indications and VL monitoring for switching ART, a therapeutic strategy better personalized to each patient in order to maintain an undetectable VL [8, 9]. In a context of resourcelimited settings like Cameroon with more limited therapeutic options, VL monitoring is not generally available and ART failure is often identified using CD4 cell count monitoring and clinical criteria $[10,11]$. In this context, it is important to know more about the virological response (VR), i.e. the rate of ART failure by measuring the VL, the percentage of patients switching from a firstline to second-line ART regimens and to identify which patients are at risk for ART failure. This may help to implement and develop more tolerable and less expensive second-line ART regimens with the ultimate effect of improving survival of PLHIV and reducing the risk of HIV transmission $[11,12]$.

The greater VR among PLHIV on first-line regimens is observed and reported wherever HIV infection prevails throughout Low- and Middle-Income Countries. The variation in proportion of patients failing first-line ART observed in the field is remarkably high and variable, ranging from 8 to $16.9 \%$ in Africa [11-19] and from 8.9 to 13\% elsewhere [20-22]. The few retrospective studies conducted at Accredited HIV Care Center (AHCC) in the Northwest, Southwest and Littoral regions of Cameroon have shown treatment failure on first-line ART between 16 and $23.2 \%$ [2, 23-25]. The rate of patients switching to second-line ART also varies and ranged from 3.5 to $30 \%$ in Africa [26-29]. The factor accounting for the heterogeneity in rates of treatment failure on first-line ART, virological failure (VF) and switching to second-line ART are not clearly understood as the definition of the virological outcome varies across studies, but are thought to involve demographic, clinical and treatment factors [21, 24, 25, 30-34]. As a prospective and longitudinal study, we aimed to assess (i) the rates of VF, (ii) the proportion of patients that switch to second-line ART and (iii) the proportion of patients who experience viral load rebound (VLR). The ultimate aim of this study was to identify the risk factors directly associated to VF.

\section{Methods}

\section{Study area and the accredited HIV care center}

The Laquintinie Hospital of Douala (LHD) is located in the 1st health district of the Douala, Littoral region of Cameroon. Douala has an estimated average annual population growth rate of $5 \%$ for the last 30 years and a current population of approximately 2,500,000 inhabitants (officially 1,931,977). It is the largest city of Cameroon and is organized in two institutional levels, an urban community and six sub-divisions.

The LHD houses an AHCC for HIV/AIDS (91\% of attendees are adults versus $9 \%$ children and adolescents) and a virology laboratory for assessing the quantification of HIV-1 RNA plasma VL infections. This AHCC is the reference center that supports PLHIV in the Littoral region since 1998. By 2014, the LHD followed about 5000 adult PLHIV, including about 4500 under ART treatment. For all PLVIH on ART, a VL request was made 12 months after the initiation of ART to check its effectiveness. If the VL was $>1000$ copies, a psychosocial trained agent conducted intensive counseling on therapeutic education with the patient for three months, and the VL is retested three months later. If the VL remained detectable, 2nd line ART with protease inhibitors available as part of the program, was prescribed. 
The threshold for VF of HIV VL was 5000 copies/mL until March 2015, and then the threshold was reduced to 1000 copies $/ \mathrm{mL}$ according to the recommendations of the WHO guidelines on the care of PLHIV. The 2nd line ARTs, including protease inhibitors, have only been available since the end of 2008. Prior to this date, patients diagnosed with clinical or immunological failure were maintained on first-line therapy after continuous reinforcement of therapeutic compliance. Moreover, the AHCC fulfills the ethical requirements for such an activity in terms of medical monitoring and maintaining the confidentiality of the PLHIV patient population.

\section{Overall study design and population}

From November 2014 to February 2016, we conducted a prospective, longitudinal cohort study among adult PLHIV attending the AHCC of the LHD. Eligibility for participation was defined as patients (i) aged 18 years or older, (ii) under treatment with first-line ART for at least 12 months by the time of enrollment, (iii) followed at the AHCC of the LHD, and (iv) having at least two measures of VL between 12 and 24 months after initiation of ART. Pregnant women, as they have different follow-up for the prevention of mother-to-child transmission (PMTCT), and patients who were already on second-line ART at the time of recruitment were excluded.

We used a convenience non-probability sampling applicable in this study. To limit the selection and information bias, participants were enrolled consecutively and participation in the study was voluntary, anonymous and without compensation.

\section{Data collection and studied variables}

The data was collected using a structured questionnaire which was administered by the principal investigator with assistance from research assistants. Interviewer-administered questionnaires and data collection sheets were used to collect data on socio-demographic characteristics (age, gender, place and year of birth, education and occupation, family and socio-economic background) and adherence. In the second part of data collection, the administered treatment, date of initiation, WHO stage and clinical course, HIV type and the CD4-T lymphocyte counts were obtained from the clinical records of patients.

In the third part, we evaluated the VR (VF, VLR and virological success-VS) and the number of patients switching to second-line ART. Two VL results between 12 and 24 months after ART initiation $<1000$ copies $/ \mathrm{mL}$ or the 1 st $\mathrm{VL} \geq 1000$ copies $/ \mathrm{mL}$ and the 2 nd $\mathrm{VL}<1000$ copies/mL defined "the patients who had a VS". Two consecutive VL were $>1000$ copies / $\mathrm{mL}$ (2nd VL $\geq 1$ st $\mathrm{VL}>1000$ copies $/ \mathrm{mL}$ ) after ART initiation defined "the patients who had a VF". The VL > 250 copies/mL at the second time point following an undetectable $\mathrm{VL}(\mathrm{VL}<$
250 copies $(\mathrm{mL}$ ) at the first time point defined "the patients who had a VLR".

Switching to 2nd line ART was defined as "patient being switched from a nucleoside reverse-transcriptase inhibitor and non-nucleoside reverse-transcriptase inhibitor regimen to a protease inhibitor based ART regimen".

The time between the date of starting first-line ART and the date of the first diagnosis of VF was considered as the time to VF (TVF) and the time to switching to second-line ART was defined as the time between the date of starting first-line ART and the date of switching to a second-line ART.

\section{Quantification of plasma HIV-1 RNA}

Extraction and purification of the plasmatic RNA were performed with the "NORDIAG Arraw" automaton and the "Viral RNA Extraction" kit from DiaSorin Ireland Ltd. according to the manufacturer instructions. The quantification of HIV-1 load was performed by TaqMan Real-Time PCR assay (Generic HIV VL assay Biocentric ${ }^{\oplus}$, Roche Diagnostics Systems, France) originally described by Rouet and collaborators in the ANRS HIV quantification working group [35]. The quantification limits range between 500 copies per $\mathrm{mL}$ (2.7 log copies per $\mathrm{mL}$ ) and 5.000,000 copies per $\mathrm{mL}$ (6.7 log per $\mathrm{mL}$ ) on samples from patients following the manufacturer's procedure. The lower detection limit of either 250 copies per $\mathrm{mL}(2.5 \log$ per $\mathrm{mL})$ of this diagnostic system was used to define virological suppression.

\section{Statistical analyses of data}

Qualitative variables were expressed as frequencies while numerical variables were presented as mean and Standard deviation (SD) for data following the normal distribution or as mean and interquartile $25-75 \%$ percentile (IQ:25-75) for data not following the normal distribution. The bivariate analysis was performed with the exact Fisher test for the qualitative variables, and a nonparametric test the Wilcoxon test for the quantitative variables. All statistical analyses were performed using Stata software (version $11 \mathrm{SE}$ ). The Odd ratios (OR) and the association of each explicative variable and studied variable was estimated using a logistic regression model to investigate whether some factors were the independent predictor variables of VF. Only $p<0.05$ values were considered statistically significant in all analyzes.

\section{Results}

Baseline characteristics of participants in population survey

During the study period, a total of 3890 PLHIV-1 (positive HIV-1 test and CD4 counts < 350 copies per mm3) on first-ART were regularly followed at the day-care hospital (Fig. 1). Of these, 330 (8.5\%) initiated their ART 
for 12 months between January and December 2013 and followed up for 15 months after. Less than half (150, 45.5\%) had at least one HIV VL test. Among them, $26.7 \%$ were lost to follow-up, $2.7 \%$ declined to participate and $36.7 \%$ had only one VL, yielding 51 patients included in the study.

The mean age of the 51 PLHIV followed-up was 39.8 (min-max: 22-71) years, with a female/male sex ratio of 2.4. Patients aged 30-39 years represented the largest age group, accounting for $41.2 \%$ of the participants. Globally, the female participants were significantly younger than males (37 years vs 45 years old, $p=0.006$ ). Most participants were single, and there was a statistically significant difference in the distribution of marital status by sex: the majority of women were single, whereas most men were married $(p=$ 0.043). Overall, there was also a statistically significant difference in the distribution of occupational activity between male and female. The majority of women were unemployed $(55.6 \%$ vs $26.7 \%$ of males) whereas far more men than women had a stable activity in the public/private sector ( $20.0 \%$ vs $2.8 \%$ for females), and the frequency of this distribution was statistically significant different $(p=0.038)$. Finally, no difference was observed for the educational level between women and men $(p=0.122)$.

\section{Baseline description of virological response}

The median time between the 1st VL and 2nd VL was 10.6 (IQ25-IQ75: 8-14) months. About two-thirds of participants $(35 / 51,68.6 \%)$ had an undetectable VL at the 1st test. One patient was switched to the second-line therapeutic protocol after the 1st VL result (384.892 copies $/ \mathrm{mL}$ ) and then achieved an undetectable $\mathrm{VL}$ at the 2nd test. Among patients with undetectable VL at the 1 st test, $80 \%$ (28/35) maintained undetectable VL and 5 (14.3\%) with $\mathrm{VL}>1000$ copies $/ \mathrm{mL}$ at the 2nd test. Among patients with detectable VL at the 1st test, 3/16 patients achieved adequate virological suppression at the 2nd test, and the VL was undetectable in two of these three patients. Among patients with VL $>1000$ copies/ $\mathrm{mL}$ at the 1 st test, $4 / 15$ (26.7\%) had their 2nd test between 3 and 6 months after the 1st VL measure. Overall, $60.8 \%$ were in VS, $25.5 \%$ in VF and $13.7 \%$ in VLR. The mean TVF was 25.5 (IQ25-IQ75: 23-29) months.

\section{Socio-demographic characteristics-based virological response}

No patient with a higher level of education was in VF (Table 1). VR was related to the level of education and patients with low educational level were more at risk of VF. VF was statistically more common among patients with none/primary education than patients with secondary

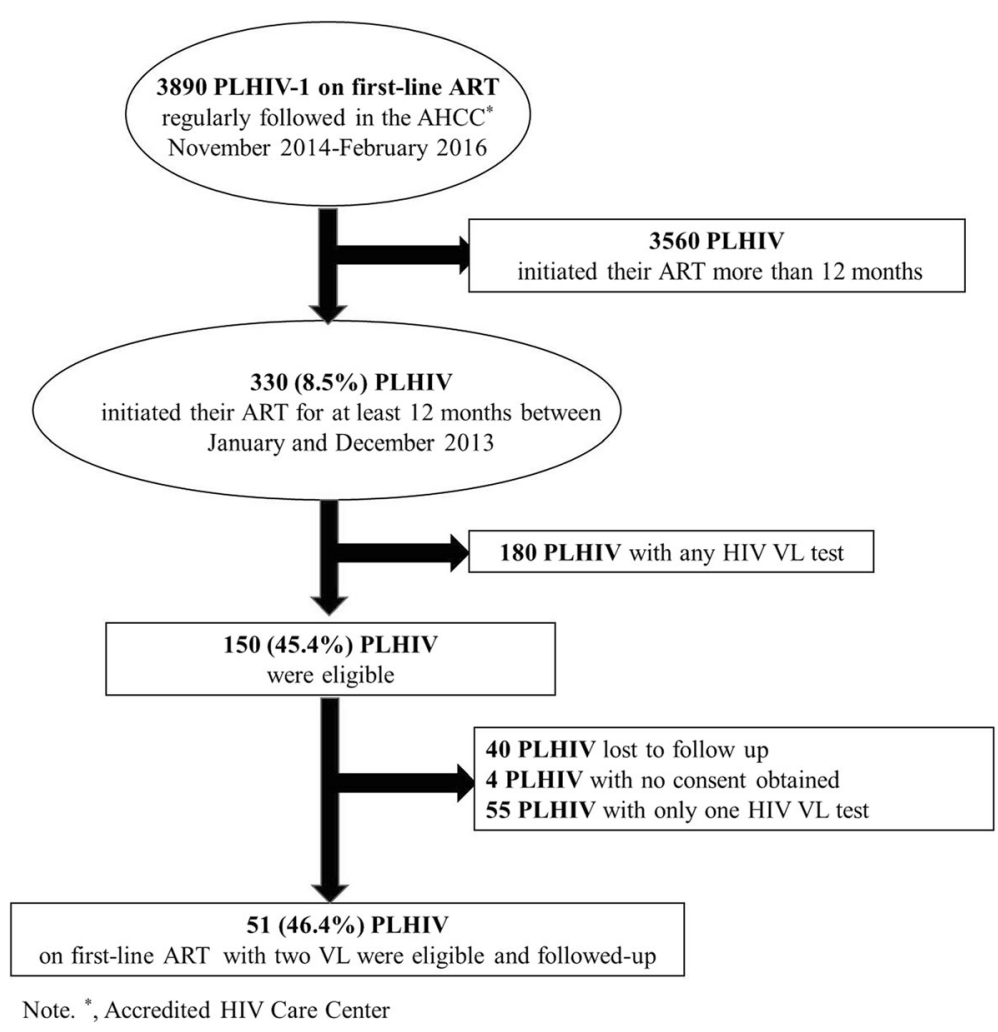

Fig. 1 Flow chart of selected adults living with HIV in the Accredited HIV Care Center 
Table 1 Patient Characteristics-based virological response

\begin{tabular}{|c|c|c|c|c|c|}
\hline Variables & Virological Success 31 (60.8) & Virological Failure 13 (25.5) & Virological Rebound 7 (13.7) & Total 51 & $p^{ \pm}$ \\
\hline \multicolumn{6}{|l|}{ Gender } \\
\hline Male & $11(73.3)$ & $1(6.7)$ & $3(20.0)$ & $36(70.6)$ & Reference \\
\hline Female & $20(55.6)$ & $12(33.3)$ & $4(11.1)$ & $36(70.6)$ & 0.121 \\
\hline Mean Age (IQ25-75\%), years & $41.3(12.0)$ & $35.7(6.1)$ & $40.7(10.2)$ & $39.8(10.7)$ & 0.104 \\
\hline \multicolumn{6}{|l|}{ Education level } \\
\hline Out-of-school+Primary & $4(23.5)$ & $7(41.2)$ & $6(35.3)$ & $17(33.3)$ & Reference \\
\hline Secondary & $21(75.0)$ & $6(21.4)$ & $1(3.6)$ & $28(54.9)$ & $0.020^{*}$ \\
\hline Higher education & $6(100)$ & $0(0)$ & $0(0)$ & $6(11.8)$ & $0.033^{*}$ \\
\hline \multicolumn{6}{|l|}{ Matrimonial status } \\
\hline Single & $13(56.5)$ & $8(34.8)$ & $2(8.7)$ & $23(45.1)$ & Reference \\
\hline Married & $16(72.7)$ & $3(13.6)$ & $3(13.6)$ & $22(43.1)$ & 0.110 \\
\hline Widower & $2(33.3)$ & $2(33.3)$ & $2(33.3)$ & $6(11.8)$ & 0.532 \\
\hline \multicolumn{6}{|l|}{ Occupation } \\
\hline None & $14(58)$. & $7(29.2)$ & $3(12.5)$ & $24(47.1)$ & Reference \\
\hline Executing agent & $13(56.5)$ & $6(26.1)$ & $4(17.4)$ & $23(45.1)$ & 0.587 \\
\hline Public/private sector employee & $4(100.0)$ & $0(0)$ & $0(0)$ & $4(7.8)$ & 0.242 \\
\hline \multicolumn{6}{|l|}{ Attend IEC } \\
\hline None & $13(54.2)$ & $7(29.2)$ & $4(16.7)$ & $24(47.1)$ & Reference \\
\hline Periodically & $4(40.0)$ & $5(50.0)$ & $1(10.0)$ & $10(19.6)$ & 0.263 \\
\hline Regularly & $14(82.4)$ & $1(5.9)$ & $2(11.8)$ & $17(33.3)$ & $0.055^{*}$ \\
\hline
\end{tabular}

Data represent the number (\%) of the variables studied unless indicated; ${ }^{f}, p$ was calculated by comparing the class of virological success (VS) vs virological failure (VF); ${ }^{*}$, Statistically significant difference

$(\mathrm{OR}=0.12, p=0.020,95 \% \mathrm{CI}: 0.035-0.751)$ or higher education ( $\mathrm{OR}=0.307, p=0.033,95 \% \mathrm{CI}: 0.000-0.922)$. More than $45 \%$ of patients were not attending informationeducation-communication (IEC) sessions (Table 1). The reasons cited were ignorance of the existence of IEC for $66.7 \%$ and occupational constraints for $33.3 \%$ of patients. There was no statistically significant difference between VF and VS according to attending or not IEC sessions. Among patients who participated in the IEC, however, patients who attended only periodically had 17 times the risk of VF compared to patients who attended IEC regularly $(\mathrm{OR}=17.50$, $p=0.020$, CI95\%: 1.56-196.32).

No statistically significant differences were observed with regard to the other variables analyzed.

\section{Biological, clinical and therapeutic characteristics-based virological response}

At ART initiation, $62.7 \%$ of patients had CD4 $\leq 200$ cells/ $\mu \mathrm{L}$ and $9.7 \%$ had CD4 > 350 cells/ $\mu \mathrm{L}$ (Fig. 2). Mean CD4 cells count was not significantly different between patients who ultimately experienced VS (196, CI95\%: 22-329) and patients who ultimately experienced VF (200, CI95\%: 100-225). The same trend was observed with the WHO stages at the initiation where most of them were in the WHO stage II (34.29\%) and III (28.57\%).
Most patients reported good adherence to prescribed first-line ART regimens with respect to doses (96.1\%), but about half $(26,51 \%)$ did not respect the schedule as prescribed. Non-respect for the dosing schedules was significantly associated with VF (42.3\%) compared to VS (38.5\%) $(\mathrm{OR}=11.55$, CI95\%:2.14-62.24, $p=0.004)$. The reasons for not respecting the schedules (not mutually exclusive) were forgetfulness (57.7\%), occupational constraints (34.6\%) and $11.5 \%$ did not know that it was necessary to respect the schedules as prescribed. Forgetfulness was 10 times more common among patients with VF than among patients with VS (OR = 10.67, CI95\%:1.39-82.03, $p=0.023$ ). In addition, 5 of the 7 patients with a VLR did not respect the schedules as prescribed and forgetfulness was mentioned for all.

Among all 51 patients, 30 (58.8\%) had stopped their treatment, mainly due to the stock-out of antiretroviral drug supplies in the AHCC $(21 / 30=70 \%)$ (Fig. 2). One patient stopped ART due to hospitalization for coma, and another stopped ART due to traveling. Globally, the mean duration of ART rupture was 50.5 (IQ25IQ75: 30-60) days among all patients, 74.7 (IQ25IQ75: 25-90) days in the group who stopped ART voluntarily, and 40.1 (IQ25-IQ75: 21-60) days in the group who stopped ART due to ART stock-out. The patients with VF had a mean duration of ART rupture (73.2, IQ25-IQ75: 0-90) statistically higher than 

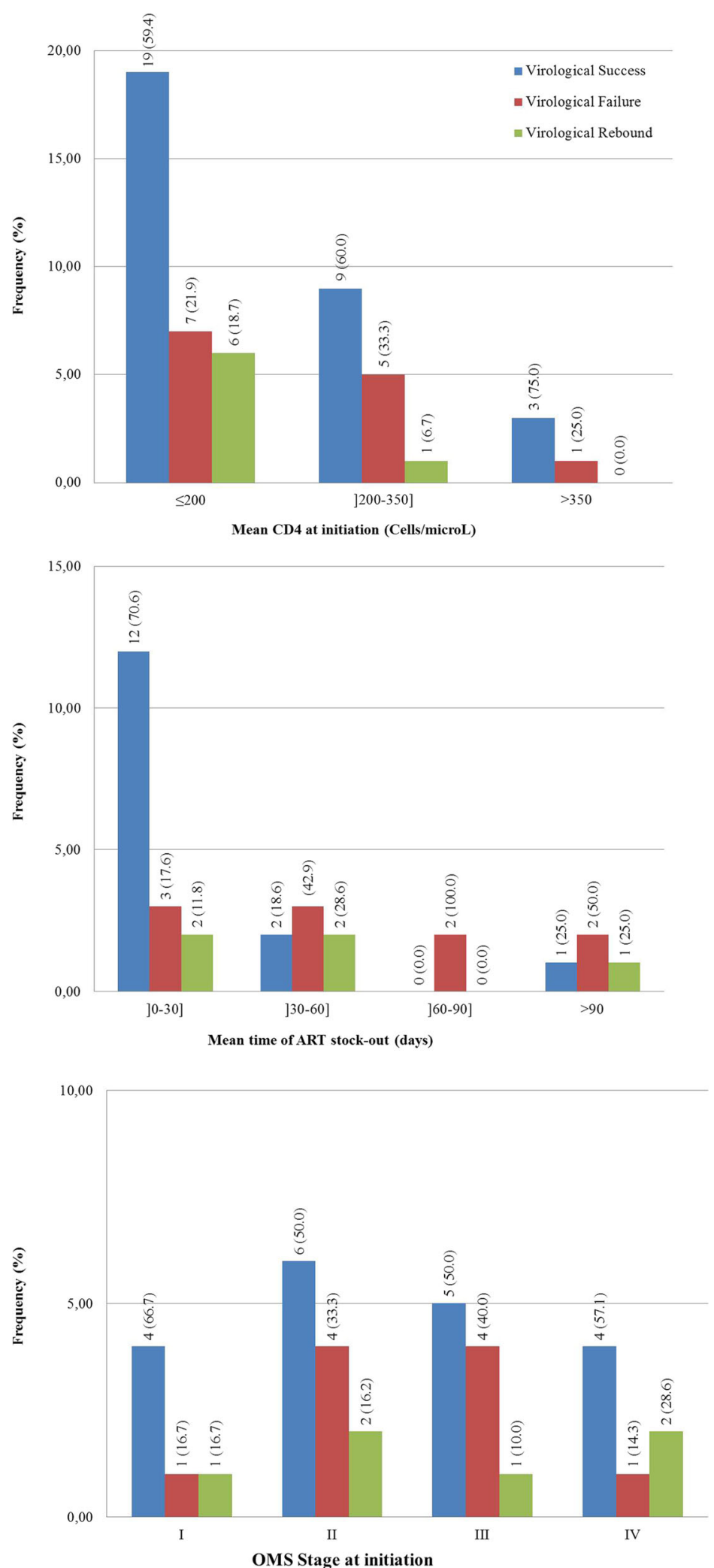

Fig. 2 Virological response according to biological, clinical and therapeutic characteristics 
those with VS (32.1, IQ25-IQ75: 14-30) $(\mathrm{OR}=1.04$, CI95\%: $1.00-1.07, p=0.032$ ).

At the time of enrollment, the majority $(62.7 \%)$ of patients were on $3 \mathrm{TC}+\mathrm{TDF}+\mathrm{EFV}$ regimens, $27.4 \%$ were on $3 \mathrm{TC}+\mathrm{NVP}+\mathrm{AZT}, 7.8 \%$ on $3 \mathrm{TC}+\mathrm{TDF}+\mathrm{NVP}$ and one patient on 3TC + EFV + AZT (Fig. 3). Between 1st VL and 2nd VL, 15 (21.5\%) patients switched to another first line treatment: 1 changed 4 times, 6 changed thrice and 8 changed twice. These changes were due to the intolerance of certain molecules in these patients. Of the 13 patients in VF, 8 (61.54\%) were under TDF + 3TC + EFV at the initiation (Fig. 3). VF was greater in patients who started treatment with the TDF $+3 \mathrm{TC}+\mathrm{EFV}$ regimens compared to those who had taken AZT $+3 \mathrm{TC}+\mathrm{NVP}$ regimens at the initiation, but this difference was not statistically significant $(p=0.12)$. Cases of VLR were observed in each ART protocol on which patients were initiated. After the 2nd VL, 8/13 (61.5\%) patients in VF were switched to a 2nd ART protocol. Four patients were switched to LPV/ $r+T D F+3 T C$, and the other four patients were switched to $\mathrm{LPV} / \mathrm{r}+\mathrm{AZT}+3 \mathrm{TC}, \quad \mathrm{LPV} / \mathrm{r}+\mathrm{ABC}+3 \mathrm{TC}, \quad \mathrm{LPV} / \mathrm{r}+$ $\mathrm{ABC}+\mathrm{ddl}$ and $\mathrm{ATV} / \mathrm{r}+\mathrm{ABC}+3 \mathrm{TC}$. The mean TSART was 25.50 (IQ25-IQ75: 22.5-29.75) months.

\section{Factors independently associated with vitological failure}

We considered VF to include patients with VLR. After adjusting for covariates associated with VF in univariate analyses, poor medication adherence $(\mathrm{OR}=7.8$; CI95\%: $1.56-34.90 ; p=0.012)$ and no education/primary education $(\mathrm{OR}=11.38$; C195\%: 2.41-53.76; $p=0.002)$ remained independently associated with VF compared with reference groups. The same results are preserved even excluding those in VLR. Low attendance at IEC and ART rupture are not associated significantly with failure.

\section{Discussion}

To our knowledge, this is the first study on virological follow-up among HIV-positive adults on first-line ART in Cameroon and that highlights the VR in a prospective study.

According to the WHO recommendations, the VL should be carried out 6 months after ART initiation (if possible) and then at least every 12 months to identify compliance/adherence to treatment and to determine if the patient should be switched to another treatment regimen. Changing the ART regimen is often necessary after treatment failure, and the new second-line regimen becomes necessary in order to reduce the accumulation of mutations related to ARV resistance and to improve clinical outcomes [26, 27]. In countries with limited access to VL tests, suspected ART failure are supported by immunological and/or clinical confirmation 6 months after ART initiation and immunological tests must be performed every 6 months $[28,29]$. However, because most patients with HIV in care now receive ART, the rationale for frequent $\mathrm{CD} 4$ monitoring is weaker.

During the period of follow-up of patients, only 51 $(15.5 \%)$ of the 330 patients who were initiated on ART in 2013 had at least two VL between 12 and 24 months after initiation on ART. In a recent retrospective study, $23.3 \%$ of 830 patients had VL testing, and all had only

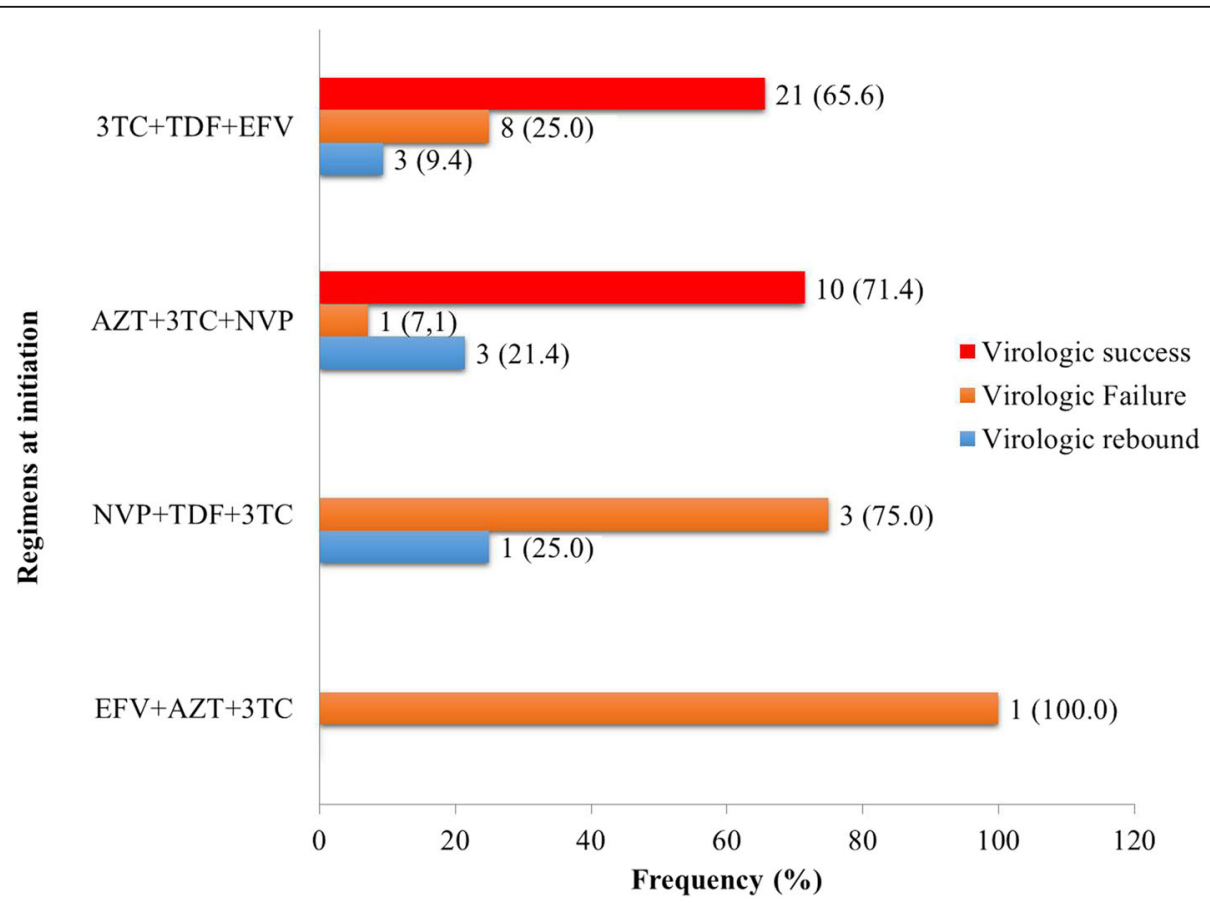

Fig. 3 Sustained Virological Response at 12 and 24 months according to ART at initiation 
one VL test [36]. There are several explanations to the low access to VL testing uptake in different centers in Cameroon. Given its high overhead costs estimated at $\$ 8,65$ per test, more patients have limited access to VL monitoring due to the management of the VL test by the patient himself. Another explanation would be the laboratories lack reagents to conduct VL testing. It is also reported the lack of adequate viral testing equipment in laboratory infrastructures. In these conditions, limited information about success in the ART programs is available due to low VL testing rates reported in these two different studies. Moreover, it is accepted that access to a targeted VL strategy to confirm failure suspected based on immunological or clinical criteria should be used to avoid unnecessary switching to second-line ART. To raise hopes towards achieving the VL testing, the Cameroonian government subsidized prices for biological monitoring of PLHIV, under ART few months after the end of our study i.e. in May 2016. For the implementation, it has set up laboratories' enrollment plan for conducting the VL test in each region that is territorially competent and organized in a network.

None of the patients died during the follow-up, all the patients benefited from an interview to reinforce the observance of the treatment after the first VL. The lack of interview to reinforce the observance may explain the high death rate reported in the study conducted in Senegal, 7.4 and $9 \%$ per year $[37,38]$.

The results of this study show a trend towards feminization of this infection. The proportion of women $70.6 \%$ are similar to the high prevalence (between 61.8 to $72.8 \%$ ) reported recently in other areas of Cameroon in 2013 and 2014 [39-41] and in other countries [19, 42-44]. This is linked to the epidemiological, anatomical, physiological, socio-cultural and economic context of HIV infection [5, 41, 45]. Thus, effective PMTCT of HIV requires the screening and systematic treatment of all pregnant women, which significantly increases the awareness of this population group and consequently the coverage of ARV and regular follow-up in case of known HIV infection.

VS is high in this study (60.8\%), lower than the $75.7 \%$ found by Bangoura et al. in Guinean patients [15] and the 76.7\% found by Anude et al. in Nigeria [46]. A recent study conducted in Cameroon reported $94.5 \%$ of patients with VS [36]. The very short mean follow-up of 26 months in our study compared to 30 or 35 months may explain this difference.

VLR was observed in 7 (13.7\%) patients. Importantly, 5 out of the 7 patients with VLR experienced stock-out of ARVs between the 1st and the 2nd VL tests. Poor adherence to ART associated with the relapse of some patients following the 1st value of the undetectable VL may thus be one factor contributing to this VLR.
Our findings showed a VF in $25.5 \%$ of patients. This is consistent with the findings of different studies in Africa from 2007 showing a VF prevalence ranging from 2.8 to $36 \%$ and immunological failure-IF from 7 to $30 \%$ [15-19, 37, 38, 47-50]. In Cameroon, retrospective cross-sectional assessments conducted at different sites reported VF of $23.2 \%$ in Northwest, $16 \%$ in South-West and $17.6 \%$ in the Central region [23, 24, 31, 36, 51]. These variations in prevalence of VF are explained partly by the fact that treatment failure was diagnosed differently (clinical, immunological or virological) across these studies. Sow et al. in Senegal considered both clinical and immunological/ virological failures in the evaluation of VF [17], while Zoufaly et al. in Cameroon and De Beaudrap et al. in Senegal defined VF as a VL $>1000$ copies / $\mathrm{mL}[18,48]$.

Our findings did not show a higher risk of VF in men as in previous studies conducted in Cameroon, where men were associated with VF $(\mathrm{OR}=2.18,95 \% \mathrm{CI}$ : 1.31 to $3.62, p=0.003)$, and lower immunologic reconstitution (coefficient: -58.7 at month $24,95 \%$ CI: -100.8 to 16.6, $p=0.006$ ) [52]. Another study conducted in Nigeria had found that only IF was associated with male gender $(\mathrm{OR}=1.46,95 \% \mathrm{CI}: 1.04-2.45, p=0.004)$ [46]. This difference may be explained by the relatively small sample size of our study (51 vs 459 in the other study in Cameroon and 628 in Nigeria). Although the associations of virological and immunological failure can differ since both conditions can also exist independently, IF normally occurs after VF and can subsequently co-exist with each other $[46,53]$. In addition, our study strongly suggests that patients with none/primary education are a high risk of VF compared to the secondary or higher education. VF was also related to non-adherence, specifically the non-compliance with medication hours. The main reason for non-compliance with medication hours reported in more than half of the patients was forgetfulness. Occupational constraints and lack of understanding that it was necessary to respect the schedules as prescribed were also cited. This confirms the results of two studies conducted in Cameroon and Nigeria [40, 46]. The majority of patients with VF were in WHO stages II and III, but no statistically significant association between WHO stages and VF was found. These results are similar to results reported in Brazil [54] and in many parts of Africa [19, 23, 55].

\section{Limitations and strengths}

Despite the small sample size, this study presents several strengths. Compared to previous reports and to our knowledge, this is the 1st study from Cameroun to investigate virological follow-up among HIV-positive adults on first-line ART in a prospective study. The main problems encountered in longitudinal studies are the high cost, the extremely long time required to obtain results and the loss 
of follow-up often important. To overcome these two limitations, many studies are carried out retrospectively from clinical records, as was the study conducted by Sow et al. in Senegal $[17,18]$. Some authors have conducted multicentric studies including between 4 and 11 sites of patient inclusion. This was the case with the cross-sectional studies carried out in Ivory Coast and in Guinea Conakry, each with a measure of VL in PLHIV under ART for at least 6 months $[15,16]$. In addition, the generic test of HIV viral load test currently used in the AHCC for HIV/AIDS laboratory only amplifies HIV-1, which does not allow an actual estimate of the value of the VL in case of coinfection or superinfection of HIV -2 .

\section{Conclusion}

Very few patients had done two VL tests as recommended at 12 months after the initiation of ART to check the effectiveness of ART. Approximately 1 in 4 patients had VF and most of them had CD4 Tlymphocytes $<200$ cells $/ \mathrm{mm} 3$. Low educational level and non-compliance to dosing schedules were likely associated with VF. As a surveillance tool, the VL should be available in the care centers, patients may be incorrectly switched to second-line ART on the basis of IF.

\section{Abbreviations}

3TC: Lamuvidine:; ABC: Abacavir; AHCC: Accredited HIV care center; AIDS: Acquired immune deficiency syndrome; ART: Antiretroviral therapy; ATC: Accredited treatment center; ATV/r: Atazanavir+ritonavir; AZT: Zidovudine; ddl: Didanosine; EDS-MICS: Enquête Démographique et de Santé et à Indicateurs Multiples; EFV: Efavirenz; HIV: Human immunodeficiency virus; IEC: Information, education and communication; IF: immunological failure; LHD: Laquintinie hospital of Douala; LPV/ r: Lopinavir+ritonavir; LPV/r: Lopinavir+ritonavir; mL: Milliliter; PLHIV: People living with HIV; PMTCT: Prevention of mother-to-child transmission; RNA: Ribonucleic acid; TDF: Tenofovir; VF: Virological failure; VL: Viral load; VLR: Viral load rebound; VS: Virological success; WHO: World health organization

\section{Acknowledgements \\ We are very grateful to the questionnaire respondents who agreed to participate in this study. We express our gratitude to the AHCC of LHD for their support and cooperation during the survey. Thanks to Mr. Eboumbou M., Buhchu Franklin and Dr. Ayong L. who reviewed and revised the manuscript for language editing. Statistical analysis and the interpretation of data were supported by International Society for Health Research and Training (ISRT-Health), a local Lecturer network.}

\section{Authors' contributions}

CEEM, JPME and MM participated in project conceptualization, planning and interview guide preparation. The interview was conducted and data were collected by JPME and SBE, two Master's degree students supervised by CEEM and SHM. COE overlooked the process of data analysis. CEEM, JPM and CIP drafted the manuscript and all authors revised and approved the final version of the manuscript.

\section{Funding}

No source of funding has been obtained to conduct the study. ISRTH was involved in the data analysis.

\section{Availability of data and materials}

All data underlying the findings described in this manuscript are fully available without restriction and, have been presented in the manuscript.

\section{Ethics approval and consent to participate}

This study was conducted in accordance with ethics directives related to research on humans in Cameroon. The study was reviewed and approved by the Institutional Health Research Ethics Committee of the University of Douala, and administrative authorization was obtained from the LHD. Before enrollment and the administration of questionnaire, subjects were informed on the purpose and process of the investigation (background, goals, methodology, study constraints, data confidentiality, and rights to opt out from the study), and a written informed consent form and assent form validated by a signature was obtained from participants or from the parents/ tutors of children/adolescents prior to inclusion of all participants.

\section{Consent for publication}

Consent to publish has been obtained from all included persons in the study.

\section{Competing interests}

The authors state no conflict of interest.

\section{Author details}

${ }^{1}$ Animal organisms Biology and Physiology Department, Faculty of Sciences, University of Douala, Douala, Cameroon. ${ }^{2}$ Clinical Sciences Department, Faculty of Medicine and Pharmaceutical Sciences, University of Douala, Douala, Cameroon. ${ }^{3}$ Accredited HIV Care Center of Laquintinie Hospital of Douala, Douala, Cameroon. ${ }^{4}$ Biological Laboratory, Laquintinie Hospital of Douala, Douala, Cameroon. ${ }^{5}$ Biological Sciences Department, Faculty of Medicine and Pharmaceutical Sciences, University of Douala, BP 2701 Douala, Cameroon. ${ }^{6}$ Centre Pasteur Cameroon, Douala, Cameroon.

Received: 1 March 2019 Accepted: 24 May 2019

Published online: 06 June 2019

\section{References}

1. UNAIDS. AIDS by the numbers. UNAIDS. 2013. 12p. https://www.unaids.org/ sites/default/files/media_asset/JC2571_AIDS_by_the_numbers_en_1.pdf1; Last accessed 28/05/2016.

2. UNAIDS. Global report: UNAIDS report on the global AIDS epidemic 2013. WHO library Cataloguing-in-Publication Data. 2013. 274p. https://www. unaids.org/sites/default/files/media_asset/UNAIDS_Global_Report_2013_en_ 1.pdf. Last accessed 28/05/2016.

3. UNAIDS Fact sheet. UNAIDS. 2014. 6p. http://files.unaids.org/en/media/ unaids/contentassets/documents/factsheet/2014/20140716_FactSheet_en. pdf. Last accessed 28/05/2017

4. WHO. HIV/AIDS Fact sheet $N^{\circ} 360$. WHO. 2015. http://who.int/mediacentre/ factsheets/fs360/en/. Last accessed 28/05/2016.

5. National Institute of Statistics. Cameroon Demographic and Health Survey and Multiple Indicator Cluster Survey 2011: Preliminary Report on HIV Prevalence. 2012. 16p. http://www.measuredhs.com/pubs/pdf/PR16/PR16. pdf. Last accessed 28/07/2017

6. National AIDS Control Committee/Central Technical Group. The impact of HIV and AIDS in Cameroon through 2020. Ministry of Public Health (Cameroon). 2010. 30p. http://www.healthpolicyinitiative.com/Publications/Documents/ 1250_1_Cameroon_EN_Singles_Reduced_acc.pdf. Last accessed 22/04/2016.

7. National AIDS Control Committee//Central Technical Group. National Strategic Plan to fight against HIV, AIDS and STIs 2011-2015. Cameroon's Government. 2010. 99p. https://www.ilo.org/dyn/natlex/ docs/ELECTRONIC/99129/118193/F-746502152/CMR-99129.pdf. French version. Last accessed 02/05/2016

8. WHO Consolidated guidelines on the use of antiretroviral drugs for treating and preventing HIV infection. Recommendations for a public health approach-Second edition. WHO. 2013. 480p. http://apps.who. int/iris/bitstream/handle/10665/208825/9789241549684_eng.pdf; jsessionid=F79CA518D1C81BB22D1DD92C4DA0F507? sequence=1. Last accessed 02/12//2016.

9. Keiser O, Orrell C, Egger M, Wood R, Brinkhof MW, Furrer $\mathrm{H}$, et al. Publichealth and individual approaches to antiretroviral therapy: township South Africa and Switzerland compared. PLoS Med. 2008;5:e148.

10. Kimmel AD, Weinstein MC, Anglaret X, Goldie SJ, Losina E, Yazdanpanah Y, et al. Laboratory monitoring to guide switching antiretroviral therapy in resource-limited settings: clinical benefits and cost-effectiveness. J Acquir Immune Defic Syndr. 2010;54(3):258-68. 
11. Boyer S, March L, Kouanfack C, Laborde-Balen G, Marino P, Aghokeng AF, et al. Monitoring of HIV viral load, CD4 cell count, and clinical assessment versus clinical monitoring alone for antiretroviral therapy in low-resource settings (Stratall ANRS 12110/ESTHER) : a cost-effectiveness analysis. Lancet Infect Dis. 2013;13(7):577-86.

12. Boender TS, Sigaloff KCE, MCMahon JH, Kiertiburanakul S, Jordan MR Barcarolo J, et al. Long-term Virological outcomes of first-line antiretroviral therapy for HIV-1 in low- and middle-income countries: a systematic review and meta-analysis. Clin Infect Dis. 2015;61(9):1453-61.

13. Jespersen S, Hønge BL, Medina C, da Silva TÂD, Correira FG, Laursen AL, et al. Lack of awareness of treatment failure among HIV-1-infected patients in Guinea-Bissau Đa retrospective cohort study. J Int AIDS Soc. 2015;18:20243.

14. Fox MP, Cutsem GV, Giddy J, Maskew M, Keiser O, Prozesky H, et al. Rates and predictors of failure of first-line antiretroviral therapy and switch to second-line ART in South Africa. J Acquir Immune Defic Syndr. 2012;60(4):428-37.

15. Bangoura N, Diouara AAM, Cissé M. Quantification of viral load and resistance tests of HIV-1 to ARVs from dried blood spots samples in Guinean patients undergoing antiretroviral treatment. Afr J lab med. 2015;4(1) French article.

16. Tanon AK, Binan Y, Minta D, Ehui E, Ouattara I, Mossou C, et al. Efficiency and safety of antiretroviral treatment among the elderly in Abidjan. Mali Med. 2010;25(1):37-41 French article.

17. Sow PG, Ndiaye IP, Soumare M, Dieye AM, Traore I, Diallo FB. Study of two cases of virological failure antiretrovirals in the Institute of Social Hygiene (ISH) of Dakar. Mali med. 2011;26(3):48-52 French article.

18. Monleau M, Aghokeng AF, Eymard-Duvernay S, Dagnra A, Kania D, NgoGiang-Huong N, et al. Field evaluation of dried blood spots for routine HIV1 viral load and drug resistance monitoring in patients receiving antiretroviral therapy in Africa and Asia. J Clin Microbiol. 2014;52(2):578-86.

19. Ouedraogo SM, Zoungrana J, Sondo A, Kyelem CG, Traoré A, Hema A, et al. Sociodemographic, clinical, biological, therapeutic characteristics and determiners of immunovirologic response among infected HIV adults under antiretroviral treatment at the day hospital of Bobo-Dioulasso (Burkina Faso). RAFMI. 2014;1(2):1-44 French article.

20. Ferradini L, Laureillard D, Prak N, Ngeth C, Fernandez M, Pinoges L, et al. Positive outcomes of HAART at 24 months in HIV-infected patients in Cambodia. AIDS. 2007;21(17):2293-301.

21. Shet A, Kumarasamy N, Poongulali S, Shastri S, Kumar DS, Rewari BB, et al. Longitudinal Analysis of Adherence to First-Line Antiretroviral Therapy: Evidence of Treatment Sustainability from an Indian HIV Cohort. Curr HIV Res. 2016;14(1)

22. Kyaw NTT, Harries AD, Kumar AMV, Oo MM, Kyaw KWY, Win T, et al. High rate of virological failure and low rate of switching to second-line treatment among adolescents and adults living with HIV on first-line ART in Myanmar, 2005-2015. PLoS One. 2017;12(2):e0171780.

23. Zoufaly A, Jochum J, Hammerl R, Nassimi N, Raymond Y, Burchard GD, et al. Virological failure after 1 year of first-line ART is not associated with HIV minority drug resistance in rural Cameroon. J Antimicrob Chemother. 2014;70(3):922-5.

24. Ida PC, Same BF, Mangamba DK, Eboumbou MEC, Ngwa V, Makouet $\mathrm{N}$, et al. Treatment failure in children infected with HIV in routine follow-up in a resource-limited setting in Cameroon. Pan Afr med J. 2013;15:80 French article.

25. Endale Eyoum M. Factors associated with switch to second-line regimens in antiretroviral-treated adults living with HIV/AIDS at the HIV Care Center of Douala. Master's thesis in Pharmacy, Pharmaceutical Sciences Department, Faculty of Medicine and Pharmaceutical Sciences, the University of Douala. 2014. 58p. French file.

26. Haas AD, Keiser O, Balestre E, Brown S, Bissagnene E, Chimbetete C, et al. Monitoring and switching of first-line antiretroviral therapy in subSaharan Africa: collaborative analysis of adult treatment cohorts. Lancet HIV. 2015;2(7):e271-8.

27. ART-LINC of leDEA Study Group. Switching to second-line antiretroviral therapy in resource-limited settings: comparison of programmes with and without viral load monitoring. AIDS. 2009;23(14):1867-74.

28. Petersen ML, Tran L, Geng EH, Reynolds S, Kambugu A, Wood R, et al. Delayed switch of antiretroviral therapy after virologic failure associated with elevated mortality among HIV-infected adults in Africa. AIDS. 2014; 28(14):2097-107.

29. Landier J, Akonde A, Pizzocolo C, Haidara I, Drabo M, Pizarro L, et al. Switch to second-line ART in west African routine care: incidence and reasons for switching. AIDS Care. 2011;23(1):75-8.
30. Hassan AS, Nabwera HM, Mwaringa SM, Obonyo C, Sanders EL, de Wit TFR, et al. HIV-1 virologic failure and acquired drug resistance among first-line antiretroviral experienced adults at a rural HIV clinic in coastal Kenya: a cross-sectional study. AIDS Res Ther. 2014;11(1):9.

31. Meriki HD, Tufon KA, Afegenwi MH, Nyindem BA, Atanga PN, Anong DN, et al. Immuno-haematologic and virologic responses and predictors of virologic failure in HIV-1 infected adults on first-line antiretroviral therapy in Cameroon. Infect Dis Poverty. 2014;3(1):5.

32. RupeÂrez M, Pou C, Maculuve S, Cedeno S, Luis L. Rodriguez, et al. determinants of virological failure and antiretroviral drug resistance in Mozambique. J Antimicrob Chemother. 2015;70(9):2639-47.

33. Bacha T, Tilahun B, Worku A. Predictors of treatment failure and time to detection and switching in HIV infected Ethiopian children receiving first line anti-retroviral therapy. BMC Infect Dis. 2012;12(1):197.

34. WHO. Consolidated guidelines on the use antiretroviral drugs for treating and preventing HIV infection. Recommendations for public Health Approach. WHO. 2013. 272p. http://apps.who.int/iris/bitstream/10665/85321/ 1/9789241505727_eng.pdf. Last accessed 25/11/2016.

35. Rouet F, Chaix ML, Nerrienet E, Ngo-Giang-Huong N, Plantier JC, Burgard M, et al. Impact of HIV-1 genetic diversity on plasma HIV-1 RNA quantification: usefulness of the Agence Nationale de Recherches Sur le SIDA secondgeneration long terminal repeat-based real-time reverse transcriptase polymerase chain reaction test. J Acquir Immune Defic Syndr. 2007;45:380-8.

36. Awungafac G, Amin ET, Fualefac A, Takah NF, Agyingi LA, Nwobegahay J, Ondoa P, Njukeng PA. Viral load testing and the use of test results for clinical decision making for HIV treatment in Cameroon: an insight into the clinic-laboratory interface. PLoS One. 2018;13(6):e0198686.

37. Laurent C, Ngom-Gueye NF, Ndour CT, Gueye PM, Diouf M, Diakhate N, et al. Long term benefit of highly active antiretroviral therapy in Senegalese HIV1 infected adults. J Acquir Immune Defic Syndr. 2005;38:14-7.

38. Ba ND. Efficacy and tolerability of antiretroviral combination therapy with a non-nucleoside analogue or a protease inhibitor: Senegalese experience. Master's thesis in Medicine $N^{\circ} 45$. Faculty of Medicine, the University of Dakar. 2005. 90p. French file.

39. Mbopi-Keou FX, Voundi EV, Kalla GC, Emah I, Angwafo F 3rd, Muna W. Factors influencing initiation of antiretroviral treatment for people living with HIV in approved HIV treatment centres of Bamenda and Bertoua in Cameroon. Pan Afr med J. 2014;17:6 French article.

40. Essomba EN, Adiogo D, Koum DC, Amang B, Lehman LG, Coppieters Y. Factors associated with non-adherence of adults infected with HIV on antiretroviral therapy in a referral hospital in Douala. Pan Afr med J. 2015;20: 412 French article.

41. Mbopi-Keou FX, Nkala IV, Kalla GC, Nguefack-Tsague G, Kamga HG, Noubom M, et al. Prevalence and factors associated with HIV and viral hepatitis $B$ and $C$ in the city of Bafoussam in Cameroon. Pan Afr med J. 2015;20:156 French article.

42. UNAIDS. Global Report: UNAIDS report on the global AIDS epidemic 2013. UNAIDS. 2013; 150p. http://files.unaids.org/en/media/unaids/contentassets/ documents/epidemiology/2013/gr2013/UNAIDS_Global_Report_2013 en. pdf. Last accessed 12/07/2016.

43. Nachega JB, Hislop M, Dowdy DW, Lo M, Omer SB, Regensberg L, et al. Adherence to highly active antiretroviral therapy assessed by pharmacy claims predicts survivalin HIV-infected south African adults. J Acquir Immune Defic Syndr. 2006;43(1):78-84.

44. Oumar AA, Dao S, Diamoutene A, Coulibaly S, Koumare B, Maiga II, et al. Factors associated with antiretroviaral treatment observance at point «G» hospital. Mali Med. 2007;22(1):18-21.

45. Carcelain G., Autran B. Immunopathological mechanisms of HIV infection. Edition Paris: Dion. 2007; 42p. www.bibalex.org/supercourse/supercoursePPT/ 22011-23001/22961.ppt. French article. Last accessed 12/07/2017.

46. Anude C, Eze E, Onyegbutulem HC, Charurat M, Etiebet MA, Ajayi S, et al. Immuno-virologic outcomes and immuno-virologic discordance among adults alive and on anti-retroviral therapy at 12 months in Nigeria. BMC Infect Dis. 2013;13:113

47. Agapit X. Immuno-virologic and therapeutic follow-up of HIV infection in children monitored at the Ouagadougou pediatric hospital (ESTHER collaboration). Master's thesis in medicine, Faculty of Medicine and Pharmacy, the University of Rouen. 2012; 99p. https://dumas.ccsd.cnrs.fr/ dumas-00760197/document. French file.

48. De Beaudrap P, Thiam M, Diouf A, Toure-Kane C, Ngom-Guèye NF, Vidal N, et al. Risk of virological failure and drug resistance during first and second- 
line antiretroviral therapy in a 10-year cohort in Senegal: results from the ANRS 1215 cohort. J Acquir Immune Defic Syndr. 2013;62(4):381-7.

49. Tebit DM, Sangaré L, Tiba F, Saydou Y, Makamtse A, Somlare $H$, et al. Analysis of the diversity of the HIV-1 pol gene and drug resistance associated changes among drug-naïve patients in Burkina Faso. J Med Virol. 2009:81(10):1691-701.

50. WHO. Antiretroviral therapy for HIV infection in adults and adolescents. Recommendations for a public health approach. WHO. 2010; 156p. http:// apps.who.int/iris/bitstream/handle/10665/44379/9789241599764_eng. pdf?sequence $=1$. Last accessed 08/11/2016.

51. Aghokeng AF, Kouanfack C, Eymard-Duvernay S, Butel C, Edoul GE, Laurent C, et al. Virological outcome and patterns of HIV-1 drug resistance in patients with 36 months' antiretroviral therapy experience in Cameroon. JInt AIDS Soc. 2013;16:18004.

52. Boullé C, Kouanfack C, Laborde-Balen G, Boyer S, Aghokeng AF, Carrieri MP, et al. Gender differences in adherence and response to antiretroviral treatment in the Stratall trial in Rural District hospitals in Cameroon. J Acquir Immune Defic Syndr. 2015;69(3):355-64

53. Grabar S, Le Moing V, Goujard C, Leport C, Kazatchkine MD, Costagliola D, Weiss L. Clinical outcome of patients with HIV-1 infection according to immunologic and virologic response after 6 months of highly active antiretroviral therapy. Ann Intern Med. 2000;133(6):401-10.

54. Bathia F, Pedresso C, Netto EM, Figueiredo R, Neto LP, Brites C. Evolution of the genotypic pattern of HIV1 resistance in AIDS patients failing antiretroviral therapy. Braz J Infect Dis. 2004;8(4):281-9.

55. Yogo GMM. A Descriptive study of resistance among the first 406 Senegalese patients from Senegalese initiative to access ARVs. Master's thesis in Medicine $N^{\circ} 79$. Faculty of Medicine, the University of Dakar. 2005. 97p. French file.

\section{Publisher's Note}

Springer Nature remains neutral with regard to jurisdictional claims in published maps and institutional affiliations.

Ready to submit your research? Choose BMC and benefit from:

- fast, convenient online submission

- thorough peer review by experienced researchers in your field

- rapid publication on acceptance

- support for research data, including large and complex data types

- gold Open Access which fosters wider collaboration and increased citations

- maximum visibility for your research: over $100 \mathrm{M}$ website views per year

At $\mathrm{BMC}$, research is always in progress.

Learn more biomedcentral.com/submissions 